\title{
Morphometric analysis of three-rooted mandibular first molars in a Slovene population: a macroscopic and cone-beam computed tomography analysis
}

\author{
L. Strmšek ${ }^{1}$, I. Štamfelj ${ }^{1}, 2$ (1) \\ ${ }^{1}$ Department of Dental Diseases and Dental Morphology, Faculty of Medicine, University of Ljubljana, Slovenia \\ 2Department of Operative Dentistry and Endodontics, University Medical Centre Ljubljana, Ljubljana, Slovenia
}

[Received: 9 November 2020; Accepted: 18 December 2020; Early publication date: 22 January 2021]

Background: This study examined the root morphology of mandibular first molars (MFMs) with radix entomolaris (RE), which presents diagnostic and therapeutic challenges for clinicians.

Materials and methods: A total of 17 three-rooted MFMs were taken from a collection of extracted teeth. Root lengths and levels of furcations were measured with a digital calliper. The pulp floor configuration, root canal systems, and RE canal curvatures were evaluated using the cone-beam computed tomography scans. Results: Radix entomolaris was either located disto-lingually, with its coronal portion fixed to the distal root $(n=16)$ or mid-lingually $(n=1)$. A literature search identified four additional cases of MFMs with RE located mid-lingually. In the present study, RE was significantly $(p \leq 0.001)$ shorter than the distal root $(D R)$ and the mesial root, on average by $2.04 \mathrm{~mm}$ and $3.15 \mathrm{~mm}$, respectively. The level of the distal furcation was significantly $(p=0.003)$ lower than that of the mesiodistal furcation, on average by $1.39 \mathrm{~mm}$. The average divergence angle formed by the cervical portions of the RE and DR canals was $53.14^{\circ}$. All RE canals were severely curved $\left(>25^{\circ}\right)$ in buccolingual direction. The RE orifice was located slightly disto-lingually to considerably mesio-lingually from the $D R$ orifice.

Conclusions: The traditional assumption of a disto-lingually located RE needs to be changed, even though this is the most prevalently found variant of this anatomy. The additional variant includes the presence of a mid-lingually located RE, which has implications for the endodontic access cavity design. (Folia Morphol 2022; 81, 1: 203-211)

Key words: radix entomolaris, supernumerary root, dental morphology, dental anthropology, odontometrics

\section{INTRODUCTION}

The root complex of the mandibular first molar (MFM) possesses two roots: a mesial root (MR) and a distal root (DR). However, a third root may be pres- ent on the lingual side of the tooth or very rarely on the buccal side of the tooth [30]; the former is named radix entomolaris (RE) and the latter radix paramolaris (RP).

Address for correspondence: Dr. I. Štamfelj, Department of Dental Diseases and Dental Morphology, Faculty of Medicine, University of Ljubljana, Hrvatski trg 6, SI-1000 Ljubljana, Slovenia, e-mail: iztok.stamfelj@mf.uni-lj.si

This article is available in open access under Creative Common Attribution-Non-Commercial-No Derivatives 4.0 International (CC BY-NC-ND 4.0) license, allowing to download articles and share them with others as long as they credit the authors and the publisher, but without permission to change them in any way or use them commercially. 
The prevalence of RE shows a distinctive pattern of geographic variation [23]. Also, this root appears to be more frequent in individuals affected by Turner syndrome than in healthy individuals [17]. In North and East Asians and Eskimo-Aleuts, this trait reaches a prevalence of $>20 \%$, which sets them apart from all other human populations. By contrast, it rarely occurs in Western Eurasian, Sub-Saharan African, New Guinean, Melanesian, and Indian populations $(<5 \%)$. A recent radiographic study reported a prevalence of $2.36 \%$ (95\% confidence interval [CI] 1.61-3.42\%) for the Slovene population [27]. As such, RE is among the traits used for ancestry estimation in the context of forensic dental profiling. A recently developed web-based application rASUDAS estimates the ancestry of unknown individuals based on their suite of tooth crown and root traits, including RE [22]. In contrast, RP seems to be rare in all human populations [5].

Apart from their role in forensic anthropology, RE and RP represent a diagnostic and therapeutic challenge in clinical dentistry, particularly in oral surgery, endodontics and periodontology. First, these roots are prone to fracture during the extraction of the tooth. Second, they may be the cause of endodontic treatment failure if not identified, properly instrumented and filled. Third, their presence may contribute to localised periodontal destruction, which is probably related to the increased complexity of furcation morphology [13]. As a result of all these factors, three-rooted MFMs are lost in significantly younger patients than their two-rooted counterparts [8].

Knowledge of the morphological characteristics of three-rooted MFMs is essential for improving the success rate of various treatments and reducing the frequency of procedural complications. In the previous decade, cone-beam computed tomography (CBCT), spiral computed tomography (SCT) and micro-computed tomography (micro-CT) have been used to analyse several morphometric aspects of such teeth, including pulp chamber geometry, root canal configuration, root canal curvature and odontometric variables $[9,10,16,20,25]$. However, until now, few studies have addressed the morphology of three-rooted MFMs in European populations [4, 5, 16]. Thus, this study aimed to analyse the morphometric aspects of the external and internal anatomy of three-rooted MFMs extracted from dental patients in Slovenia.

\section{MATERIALS AND METHODS}

\section{Extracted teeth}

The Faculty of Medicine of the University of Ljubljana houses a collection of extracted teeth donated by Slovene dentists. The collection presently includes 17 three-rooted MFMs (11 right and 6 left). All of them have a lingually-located supernumerary root (RE). The teeth and their supernumerary roots were identified by the present authors. For most teeth, there was no data on the patients' gender, age, ethnic background, and the reasons for extractions.

\section{Macroscopic analysis of the external dental morphology}

The following observations and measurements were recorded:

- Position of RE: the teeth were grouped into four types $(A, B, C, A C)$ according to the classification described by Carlsen and Alexandersen [4]. Types $A$ and $B$ refer to an RE that is located directly lingually in relation to the DR, which consists of two components (divided by a longitudinal furrow) or a single component, respectively. Type $C$ refers to an RE that is located directly lingually in relation to the MR, and the intermediate type AC to an RE that is located exactly midway between the MR and DR;

- Curvature and relative length of RE: the teeth were grouped into five types (I, II, III, small type, and conical type) according to the classifications described by Ribeiro and Consolaro [19] and Song et al. [24];

- Level of root apex: distance from the apex to the cemento-enamel junction (CEJ) was measured along the tooth axis. Measurements were made for all three roots;

- Level of root furcation: distance from the lowest level of furcation to the CEJ measured along the tooth axis. The furcation between the MR and DR (mesio-distal furcation) and the furcation between the RE and DR (distal furcation) were measured, respectively;

- RE's degree of separation (in relation to the DR) was determined according to Carlsen [3]: the furco-apical extension of the DR was divided by its cervico-apical extension.

All measurements were made with a digital calliper with a resolution of $0.01 \mathrm{~mm}$ (ABS Digimatic, Mitutoyo, Japan). 


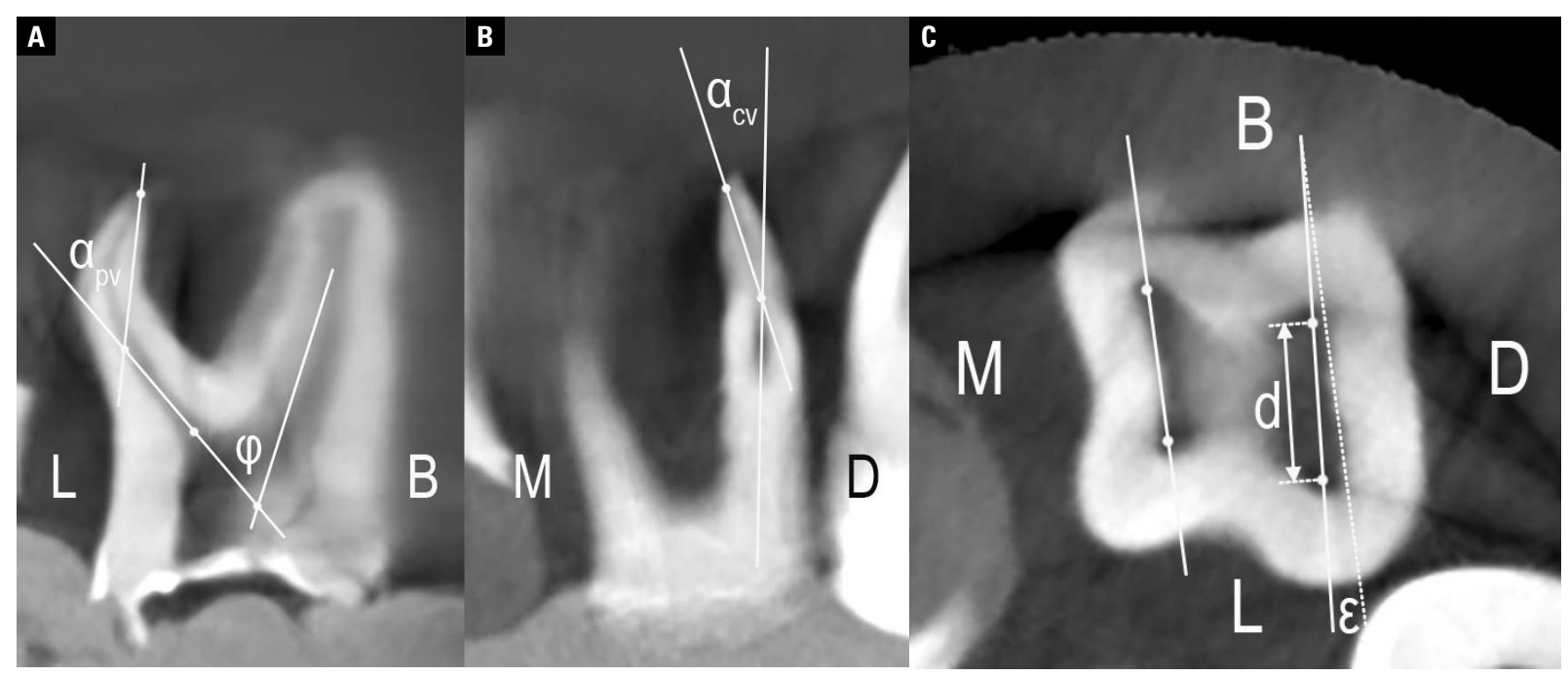

Figure 1. Cone-beam computed tomography images of the extracted mandibular first molar demonstrating measurements in a proximal view (A), clinical view (B), and on the pulp chamber floor (C); $\varphi$ — angle of divergence of the radix entomolaris (RE) canal in relation to the distal root canal; $\alpha_{\mathrm{pv}}$ - angle of curvature of the RE canal in proximal view; $\alpha_{\mathrm{cv}}$ - angle of curvature of the RE canal in clinical view; $\mathrm{d}$ - distance between distal root canal orifices; $\varepsilon$ - angle formed by lines through both mesial and both distal root canal orifices; $\mathrm{L}$ — lingual; B - buccal; $\mathrm{M}$ - mesial; D - distal.

\section{$\mathrm{CBCT}$ analysis of the internal dental morphology}

The CBCT images of the extracted teeth were taken with a Veraviewepocs 3D R100 device (Morita, Kyoto, Japan). The operating parameters were $8 \mathrm{~mA}, 90 \mathrm{kV}$, field of view $42.6 \mathrm{~mm} \times 43.0 \mathrm{~mm}$, slice thickness $1.0 \mathrm{~mm}$, and voxel size $0.125 \mathrm{~mm}^{3}$. The obtained images were analysed using i-Dixel One Volume Viewer 2.0.0 software (Morita, Kyoto, Japan).

The following observations and measurements were recorded:

- Configuration of the root canal system: the canal configuration in each root was determined and recorded by Vertucci's method [29];

- Divergence of the RE canal (in relation to the DR canal): the angle formed by lines running through the cervical portions of the RE and DR canals was measured (Fig. 1A);

- Curvature of the RE canal: the root canal curvature was measured for a proximal view (PV) (Fig. 1A) and a clinical view (CV) (Fig. 1B) using the technique described by Schneider [21]. The RE canal curvature was classified as follows: straight $\left(<10^{\circ}\right)$, moderate $\left(10-25^{\circ}\right)$, severe $\left(>25^{\circ}\right)$;

- Position of the RE canal orifice (in relation to the DR canal orifice): a line was drawn between the centres of the RE and DR canal orifices and the inter-orifice distance (d) was measured using the geometric measurement module of the software (Fig. 1C). The angle $(\varepsilon)$ formed by the lines con- necting both mesial and both distal orifices was also measured (Fig. 1C). The position of the RE canal orifice was displayed in a coordinate system with the origin in the DR canal orifice and a horizontal axis parallel with the line connecting both mesial orifices. The RE canal orifice coordinates were calculated from the measured parameters $(x=d \times \cos \varepsilon, y=d \times \sin \varepsilon)$.

\section{Data analysis}

All measurements were made independently by both authors, and the average was used for data analysis. A t test was applied to examine any statistically significant difference between the lengths of both main roots and RE, between the levels of mesio-distal and distal furcations, and between the RE canal curvature in CV and PV. A p-value of $<0.05$ was considered significant.

\section{Literature search}

A literature search for articles on MFMs with RE published until August 2019 was conducted using a PubMed database search. The following keywords were used: 'three-rooted mandibular first molar', 'radix entomolaris', 'disto-lingual root', 'additional distal root', and 'extra distal root'. Papers were retrieved and screened for three-dimensional (3D) pictures of MFMs with $R E$ (photographs of extracted teeth and 3D reconstructed CBCT, SCT and micro-CT images of teeth). Cases 


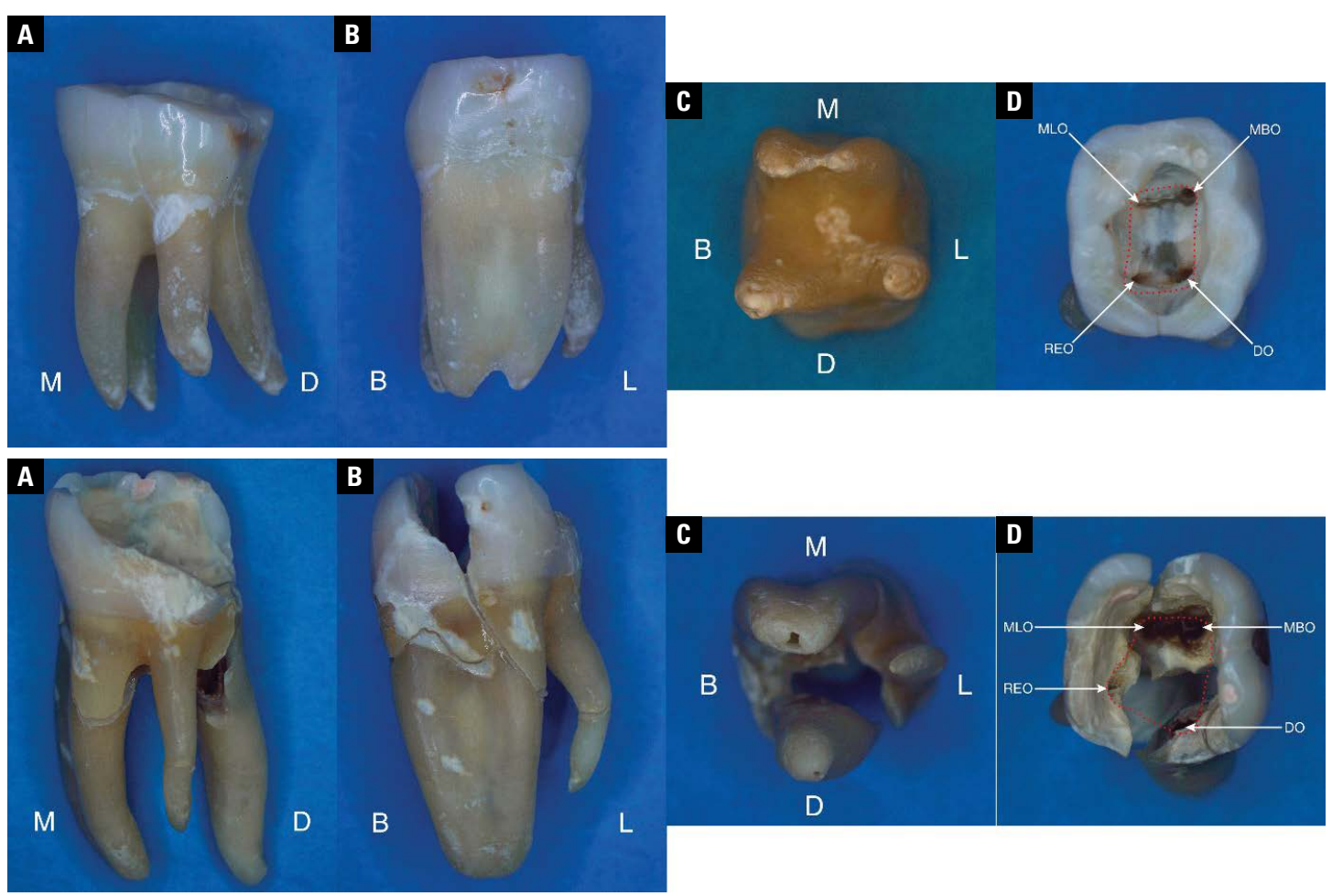

Figure 2. Right permanent mandibular first molars with type A morphology (upper row) and type AC morphology (lower row). Both specimens are displayed from the lingual side (A), mesial side (B), apical side (C), occlusal side (D); $M-$ mesial; D - distal; B - buccal; $\mathrm{L}$ — lingual; MLO — mesio-lingual canal orifice; MBO — mesio-buccal canal orifice; REO — radix entomolaris canal orifice; DO — distal root canal orifice. The red dotted line indicates the shape of the pulp floor.

of teeth depicted only two-dimensionally (periapical radiographs, CT slices) were excluded. Reference lists were checked to identify any other relevant articles.

On the selected pictures, the following observations were recorded:

- Position of RE: the teeth were grouped into four types (A, B, C, AC) according to the classification described by Carlsen and Alexandersen [4];

- Relative length of RE: it was recorded whether RE was shorter or longer than half of the length of the associated DR;

- RE's separation: it was recorded whether RE was separate or non-separate in relation to the DR.

All pictures were independently evaluated by both authors. Disagreements were resolved by joint evaluation.

\section{RESULTS}

\section{Macroscopic analysis of the external}

\section{dental morphology}

We were able to sort the examined teeth into types $A(n=16)$ and $A C(n=1)$ defined by Carlsen and Alexandersen [4]. In type $A$, the cervical part of the RE was fused with the DR, whereas in type AC the RE was located exactly midway between the MR and DR (Fig. 2). The only tooth with AC morphology was extracted from a 22-year-old female patient of Slovene origin after unsuccessful endodontic treatment. It was undoubtedly an MFM, since all three mandibular molars were present in the tooth row before extraction.

Table 1 shows the distribution of teeth according to the curvature and relative length of the $\operatorname{RE}[7,14,24]$. The average levels of the root apexes and root furcations can be seen in Table 2 . The RE was significantly $(p=0.001)$ shorter than the DR, with an average difference of $2.04 \mathrm{~mm}$ (range $0.07-3.50 \mathrm{~mm}$ ). It was also significantly $(p<0.001)$ shorter than the MR, with an average difference of $3.15 \mathrm{~mm}$ (range 1.60-4.95 mm). The level of the distal furcation was significantly ( $p=0.003$ ) lower than that of the mesio-distal furcation with an average difference of $1.39 \mathrm{~mm}$ (range 0-6.22 mm). All three roots separated at the same level in 4 MFMs ( 3 of type $A$ and 1 of type $A C$ ). In type A, $R E$ 's degree of separation, in relation to the $D R$, varied from 0.30 to 0.85 with an average value of 0.64 . 
Table 1. Curvature and relative length of the radix entomolaris, scored according to the classifications of Ribeiro and Consolaro (1997) and Song et al. (2010)

\begin{tabular}{lcccccccc}
\hline Reference & Country & Method & N & Conical type & Small type & Type I & Type II & Type III \\
\hline Song et al. [24] & Korea & CBCT & 358 & $5(1.4 \%)$ & $9(2.5 \%)$ & $29(8.1 \%)$ & $170(47.5 \%)$ & $145(40.5 \%)$ \\
Kim et al. [14] & Korea & CBCT & 507 & - & $8(1.6 \%)$ & $39(7.7 \%)$ & $141(27.8 \%)$ & $319(62.9 \%)$ \\
De Moor et al. [7] & Belgian & ET, CE & 18 & - & - & $2(11.1 \%)$ & $5(27.8 \%)$ & $11(61.1 \%)$ \\
Present study & Slovenia & ET & 14 & $0(0 \%)$ & $0(0 \%)$ & $1(7.1 \%)$ & $3(21.4 \%)$ & $10(71.4 \%)$ \\
\hline
\end{tabular}

$\mathrm{N}$ - number of three-rooted mandibular first molars; type I — straight and parallel to the distal root; type II — straight, but lingually tilted; type III — lingually tilted, and buccally curved; Small type — shorter than half the length of the distal root, Conical type — cone-shaped extension without root canal; CBCT — cone-beam computed tomography, ET — extracted teeth, $\mathrm{CE}$ - clinical evaluation during the endodontic treatment

Table 2. Levels of root apexes and furcations from the cementoenamel junction

\begin{tabular}{lccccc}
\hline Structure & Sample size & Minimum [mm] & Maximum [mm] & Mean [mm] & $\mathbf{P}$ \\
\hline Mesial root & 15 & 12.24 & 16.75 & $14.38(14.09)$ & $<0.001$ \\
Distal root & 15 & 9.82 & 14.85 & $12.30(13.64)$ & 0.001 \\
Radix entomolaris & 12 & 8.60 & 12.87 & 11.10 & 3.37 \\
Mesio-distal furcation & 16 & 2.02 & 4.85 & 4.77 & 0.003 \\
Distal furcation & 16 & 2.60 & 9.59 & 4 & \\
\hline
\end{tabular}

Numbers in parentheses indicate average root lengths for two-rooted mandibular first molars extracted from dental patients in Slovenia [15].

\section{CBCT analysis of the internal dental morphology}

The RE and DR of the examined MFMs exhibited Vertucci type I root canal system (only one DR with type III canal system was the exception). The MR showed a more variable canal configuration; however, the prevailing anatomy was type IV (10 cases), followed by type II (4 cases). The 3-2-1 canal system was observed in one case. The canal configuration in the remaining two MRs could not be determined.

Divergence of the RE canal, in relation to the DR canal varied from $30.90^{\circ}$ to $75.58^{\circ}$ with a mean value of $53.14^{\circ}$. All RE canals contained a primary curvature in the buccal direction; in one tooth, there was also a secondary apically-located curvature in the opposite, i.e. lingual, direction. In PV, all RE canals were classified as severely curved. In CV, however, only one severely curved RE canal was found. Statistical analysis showed that the average RE canal curvature was significantly $(p<0.001)$ greater in PV than in CV (Table 3 ).

The average inter-orifice distance from the RE canal to the DR canal was $3.59 \mathrm{~mm}$ (range 2.39-4.50 mm). The RE canal orifice was located disto-lingually to mesio-lingually from the DR canal orifice (Fig. 3). In the mesio-distal direction, its position varied from $1.44 \mathrm{~mm}$ mesially (type AC morphology) to $0.61 \mathrm{~mm}$ distally from the DR canal orifice.
Table 3. Curvature of the radix entomolaris root canals

\begin{tabular}{lccccc}
\hline View & $\begin{array}{c}\text { Sample } \\
\text { size }\end{array}$ & $\begin{array}{c}\text { Minimum } \\
{[\mathbf{0}]}\end{array}$ & $\begin{array}{c}\text { Maximum } \\
{[\mathbf{0}]}\end{array}$ & $\begin{array}{c}\text { Mean } \\
{[\mathbf{0}]}\end{array}$ & $\mathbf{P}$ \\
\hline Proximal & 8 & 30.71 & 69.61 & 48.48 & $<0.001$ \\
Clinical & 8 & 0.00 & 39.10 & 10.04 & \\
\hline
\end{tabular}

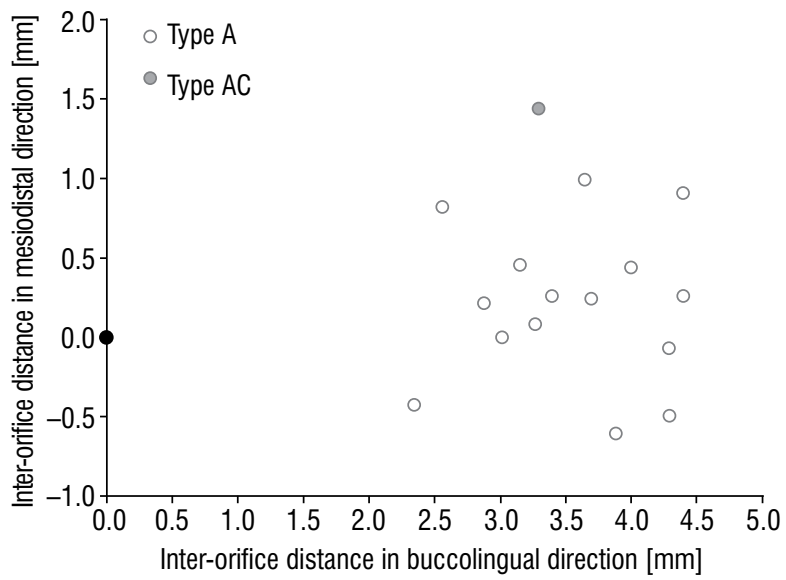

Figure 3. Position of the radix entomolaris canal orifice in relation to the distal root canal orifice. The centre of the distal root canal orifice represents the origin of the coordinate system (black circle). The horizontal coordinate axis runs parallel to the line connecting root canal orifices in the mesial root. All teeth are represented as they were from the right side. 
Table 4. Summary of the mandibular first molars with mid-lingually located radix entomolaris (type AC morphology according to the classification of Carlsen and Alexandersen [4])

\begin{tabular}{lccccccc}
\hline Tooth (FDI-notation) & Age [years] & Gender & Country & Ethnicity & Method & $\begin{array}{c}\text { Relative } \\
\text { length }\end{array}$ & Reference \\
\hline 46 & NS & Male & Canada & Inuit & ET & $<1 / 2$ & Tumer [28] \\
46 & NS & Male & Canada & Inuit & ET & $<1 / 2$ & Tumer [28] \\
46 & NS & NS & Senegal & Wolof & ET & $<1 / 2$ & Sperber and Moreau [26] \\
46 & NS & NS & Brazil & NS & Micro-CT & $>1 / 2$ & Souza-Flamini et al. [25] \\
46 & 22 & Female & Slovenia & Caucasian & ET & $>1 / 2$ & Present study \\
\hline
\end{tabular}

NS - not specified; ET — extracted tooth; micro-CT — three dimensional model of the tooth, produced from micro-computed tomography scans. The relative length indicates whether radix entomolaris was shorter $(<1 / 2)$ or longer $(>1 / 2)$ than half of the length of the associated distal root

\section{Literature search}

The literature search identified 29 relevant papers with 3D pictures of 58 MFMs with RE (39 right and 19 left). Type A morphology was identified in 54 MFMs; in three of them, RE was non-separate in relation to the DR $[4,18]$. RE shorter than half of the length of the associated DR was observed in one tooth [14]. Type AC morphology was identified in four mandibular first molars $[25,26,28]$; data on these teeth are summarised in Table 4. In three of them, RE was shorter than half of the length of the associated DR.

\section{DISCUSSION}

The material available for this study was small (17 MFMs with RE), which is a characteristic problem when studying relatively rare root traits in small ethnic areas, such as Slovenia. This is also due to the decreasing availability of extracted teeth for research purposes, which is associated with the decline in the prevalence of caries and advances in dental care in this country. Nevertheless, the teeth were well preserved, and it was possible to perform most of the observations and measurements. Moreover, in one MFM, the RE was located exactly midway between the MR and DR, corresponding to type $A C$ as defined by Carlsen and Alexandersen [4]. A tooth with such morphology has not been found even in much larger collections of extracted teeth, e.g. in the Copenhagen and Amsterdam collections that together included 87 MFMs with RE $[4,30]$.

Our finding challenges the widespread belief that RE in MFMs invariably appears disto-lingually, with its coronal portion fixed to the DR (type A variant) $[1,3,4]$. Various positional terms (disto-lingual root, supernumerary disto-lingual root, disto-lingual extra root, additional distal root and extra distal root) have almost completely replaced the more common term 'RE' in the recent dental and anthropological literature. According to the results of our literature search, only four MFMs with type AC morphology have been documented (Table 4). Surprisingly, none of the authors mentioned that this was an unusual root morphology of the MFM. In three of these teeth, RE was shorter than half of the length of the distal root. The ethnic origin of individuals with type AC MFMs was variable; however, the present study appears to provide the first description of such a tooth in an ethnic European individual.

A small number of documented MFMs with type AC morphology probably reflects the rarity with which they occur. An additional reason might be that such teeth are discarded by oral surgeons, because it is even less possible to extract them in one piece than their more prevalent type A counterparts. In our case, the tooth was extracted in several fragments that were collected and later glued together and only then the unusual root morphology became apparent. Fortunately, the lingual side of the root trunk was not damaged during extraction, and it was possible to register the position of RE in the root complex with certainty.

In our study, the RE was always longer than half the length of the DR (short and conical types absent) and most frequently (71.4\% of the teeth) tilted lingually and curved buccally (type III). A Belgian study of extracted and endodontically treated teeth [8] and a Korean CBCT-based study [15] yielded comparable results; however, another Korean CBCT-based study [26] reported similar frequencies of types II and III (Table 1).

It is often claimed in the literature that the RE is shorter than the MR and DR; however, numerical data have been presented by only a few authors. In the examined MFMs, the RE was on average $2.04 \mathrm{~mm}$ shorter than the DR and $3.15 \mathrm{~mm}$ shorter than the 
MR. Both differences were statistically significant $(p \leq 0.001)$. Our results are in line with studies on three-rooted MFMs extracted from Taiwanese [6] and Chinese patients [10]. The former reported that the RE was significantly shorter than the DR with an average of $1.48 \mathrm{~mm}$. In the later, RE was significantly shorter than both DR and MR with an average of $0.88 \mathrm{~mm}$ and $1.54 \mathrm{~mm}$, respectively. A CBCT study in Korea has shown that MFMs with RE shorter than half of the length of the associated DR represent around $4 \%$ of all cases [24]. Therefore, in MFMs, the RE mostly appears as a well-formed root approaching the length of both main roots. In the present study, the average lengths of the MR and DR were similar to those reported for two-rooted MFMs extracted from dental patients in Slovenia [15] (Table 2). These findings are of clinical significance when determining working lengths during the endodontic treatment.

Knowledge of the distal furcation level plays a significant role when planning periodontal treatment, especially because it is not possible to detect this furcation with conventional radiography. In four of the examined MFMs ( 3 type $A$ and 1 type AC), RE separated from the root trunk at the same level as both main roots, forming a trifurcation. These teeth would be suitable for resection of RE in the case of furcation involvement, because a 'normal' two-rooted morphology could be established in this manner. In the remaining 13 MFMs, the RE separated from the DR apically from the mesio-distal furcation. Therefore, distal furcation would become periodontally involved later in the disease process when the amount of periodontal tissue support may not be sufficient to allow RE resection. The level of the distal furcation was significantly $(p=0.003)$ lower than that of the mesio-distal furcation, with an average of $1.39 \mathrm{~mm}$. These results are concordant with those obtained in a Chinese study [10]. Moreover, the RE's degree of separation, in relation to the $D R$, varied considerably (from 0.30 to 0.85 ). Our literature search indicates that, in extreme cases, a complete fusion (degree of separation 0 ) between the RE and DR may also occur $[4,18]$.

In Asian populations, the root canal anatomy of the MFMs with and without RE has been comparatively studied in vivo using $\mathrm{CBCT}$ [32], and in vitro using micro-CT [9] or the method of canal staining and root clearing $[11,12]$. The MR predominantly contained type IV (29-94\%) and type II (2-31\%) canal configurations in both, the two- and three-rooted molars. In contrast, the DR less frequently contained two canals in the three-rooted molars (5-14\%) as in the two-rooted molars (28-36\%). These results, together with those from our study, indicate that the occurrence of the RE is associated with a tendency for simplification of the canal system in the DR, but not in the MR.

In all examined MFMs, the RE canal was severely curved $\left(>25^{\circ}\right)$ bucco-lingually, which is in accordance with previous studies that established a severe bucco-lingual curvature of the RE canal in $90.5 \%$ to $100 \%$ of the examined MFMs $[6,9,20]$. This pronounced curvature of the RE canal has to be taken into consideration during root canal instrumentation, because it increases the risk of complications such as over-straightening with strip perforations or instrument fractures. Yu et al. [33] showed that a significantly greater incidence of instrument separation, lateral perforation, and underfill was associated with the RE canal than with other root canals in MFMs. Also, our study showed that there was a considerable lingual inclination of the RE canal, ranging from $30.90^{\circ}$ to $75.58^{\circ}$. Therefore, the endodontic instruments have to be inserted into the RE canal from the buccal side. Worthy of note is that the two clinically relevant morphometrical characteristics of RE (buccolingual curvature and lingual inclination) cannot be visualised using conventional two-dimensional radiography.

Several authors measured the distance on the pulp floor between the orifices of the DR and RE canals. For teeth extracted from Chinese patients they reported the average inter-orifice distance of $2.93 \mathrm{~mm}$ [8], for those extracted from Korean patients of $3.77 \mathrm{~mm}$ [14], and for those extracted from Brazilian patients of $3.20 \mathrm{~mm}$ [25] and $3.93 \mathrm{~mm}$ [20]. A comparable average value of $3.59 \mathrm{~mm}$ was determined in the present study. However, in the above-mentioned studies, the position of the RE canal orifice, in relation to the DR canal orifice, has not been investigated, although it has implications for the endodontic access cavity design. We were able to demonstrate the positional continuity between the RE canal orifices located slightly disto-lingually and those located considerably mesio-lingually from the canal in the DR. Based on literature review, Abella et al. [2] suggested that the disto-lingual corner of the access cavity should extend more lingually to facilitate the localisation and access to the RE canal. To this we can add that in MFMs with type AC morphology the extension should be directed mesio-lingually (as seen in Fig. 2). 
The radiographic identification of a disto-lingually located RE (type A) may be a challenging task, because this root is mostly situated in the same bucco-lingual plane as the DR. Therefore, the additional $25^{\circ}$ mesial radiograph is essential in such cases [31]. In MFMs with mid-lingually located RE (type AC), overlapping with the DR is less likely, which makes it easier to identify by using periapical radiography. The absence of overlapping between the RE and DR appears to be the only sign indicating type $A C$ morphology on a straight periapical radiograph. CBCT overcomes these limitations and allows a reliable distinction between both morphological types of RE.

The absence of MFMs with RP in our material is not unexpected, given the rarity with which they occur. Such a tooth was not found among 1954 MFMs from the Amsterdam collection of extracted teeth [30], nor was it found on CBCT scans of 116 Brazilian dental patients [20]. However, one MFM with a separate RP and four MFMs with unseparated RP and MR were identified in the Copenhagen collection of extracted teeth [5].

\section{CONCLUSIONS}

Mid-lingual position of a RE is a rare but clinically significant anatomic variation of MFMs. This variation needs to be identified during endodontic treatment so that appropriate adjustments to the access opening can be made, and thorough debridement of the additional root canal can be accomplished. From a periodontal viewpoint, such a tooth is suitable for resection of the RE in the case of furcation involvement. This study disputes the previous assertion that an RE in MFMs always occurs on the lingual side of the main distal root. Replacement of the more inclusive term 'RE' with positional terms stating the distal position of the additional root (disto-lingual/additional distal/extra distal root) is hardly appropriate in light of the presented findings. Regardless of the RE position in the root complex, the clinician should anticipate that its root canal exhibits a lingual tilt and a severe curve toward the buccal, which cannot be detected readily on conventional radiographs.

\section{Conflict of interest: None declared}

\section{REFERENCES}

1. Abella F, Mercadé $M$, Duran-Sindreu $F$, et al. Managing severe curvature of radix entomolaris: three-dimensional analysis with cone beam computed tomography. Int Endod J. 2011; 44(9): 876-885, doi: 10.1111/j.13652591.2011.01898.x, indexed in Pubmed: 21671948.
2. Abella F, Patel S, Durán-Sindreu F, et al. Mandibular first molars with disto-lingual roots: review and clinical management. Int Endod J. 2012; 45(11): 963-978, doi: 10.1111/j.13652591.2012.02075.x, indexed in Pubmed: 22681628.

3. Carlsen O. Dental morphology. Munksgaard, Copenhagen 1987.

4. Carlsen O, Alexandersen V. Radix entomolaris: identification and morphology. Scand J Dent Res. 1990; 98(5): 363-373, doi: 10.1111/j.1600-0722.1990.tb00986.x, indexed in Pubmed: 2293344.

5. Carlsen O, Alexandersen V. Radix paramolaris in permanent mandibular molars: identification and morphology. Scand J Dent Res. 1991; 99(3): 189-195, doi: 10.1111/j.16000722.1991.tb01884.x, indexed in Pubmed: 1871529.

6. Chen $\mathrm{G}$, Yao H, Tong $\mathrm{C}$. Investigation of the root canal configuration of mandibular first molars in a Taiwan Chinese population. Int Endod J. 2009; 42(11): 1044-1049, doi: 10.1111/j.1365-2591.2009.01619.x, indexed in Pubmed: 19825040 .

7. De Moor RJG, Deroose CA, Calberson FLG. The radix entomolaris in mandibular first molars: an endodontic challenge. Int Endod J. 2004; 37(11): 789-799, doi: 10.1111/j.13652591.2004.00870.x, indexed in Pubmed: 15479262.

8. Gu Y, Lu Q, Wang H, et al. Root canal morphology of permanent three-rooted mandibular first molars - part I: pulp floor and root canal system. J Endod. 2010; 36(6): 990-994, doi: 10.1016/j.joen.2010.02.030, indexed in Pubmed: 20478452.

9. Gu Y, Lu Q, Wang P, et al. Root canal morphology of permanent three-rooted mandibular first molars: Part II - measurement of root canal curvatures. J Endod. 2010; 36(8): 1341-1346, doi: 10.1016/j.joen.2010.04.025, indexed in Pubmed: 20647093.

10. Gu Y, Zhou P, Ding Y, et al. Root canal morphology of permanent three-rooted mandibular first molars: Part III. An odontometric analysis. J Endod. 2011; 37(4): 485-490, doi: 10.1016/j.joen.2011.01.013, indexed in Pubmed: 21419295.

11. Gulabivala K, Aung TH, Alavi A, et al. Root and canal morphology of Burmese mandibular molars. Int Endod J. 2001; 34(5): 359-370, doi: 10.1046/j.1365-2591.2001.00399.x, indexed in Pubmed: 11482719.

12. Gulabivala $\mathrm{K}$, Opasanon $\mathrm{A}, \mathrm{Ng} \mathrm{YL}$, et al. Root and canal morphology of Thai mandibular molars. Int Endod J. 2002; 35(1): 56-62, doi: 10.1046/j.1365-2591.2002.00452.x, indexed in Pubmed: 11853239.

13. Huang RY, Lin CD, Lee MS, et al. Mandibular disto-lingual root: a consideration in periodontal therapy. J Periodontol. 2007; 78(8): 1485-1490, doi: 10.1902/jop.2007.060419, indexed in Pubmed: 17668967.

14. Kim Y, Roh BD, Shin Y, et al. Morphological characteristics and classification of mandibular first molars having 2 distal roots or canals: 3-dimensional biometric analysis using cone-beam computed tomography in a korean population. J Endod. 2018; 44(1): 46-50, doi: 10.1016/j. joen.2017.08.005, indexed in Pubmed: 29033084.

15. Krobot J. Velikost stalnih zob pri prebivalcih Slovenije raziskava ekstrahiranih zob [Undergraduate thesis in Slovene]. Ljubljana: University of Ljubljana; 2020. University of Ljubljana Repository.

16. Martins JNR, Marques D, Mata A, et al. Root and root canal morphology of the permanent dentition in a Caucasian 
population: a cone-beam computed tomography study. Int Endod J. 2017; 50(11): 1013-1026, doi: 10.1111/ iej.12724, indexed in Pubmed: 27883205.

17. Midtbø $M$, Halse A. Root length, crown height, and root morphology in Turner syndrome. Acta Odontol Scand. 1994; 52(5): 303-314, doi: 10.3109/00016359409029043, indexed in Pubmed: 7825400.

18. Quackenbush LE. Mandibular molar with three distal root canals. Endod Dent Traumatol. 1986; 2(1): 48-49, doi: 10.1111/j.1600-9657.1986.tb00123.x, indexed in Pubmed: 3457702.

19. Ribeiro FC, Consolaro A. Importancia clinica y antropologica de la raiz distolingual en los molars inferiors permanentes. Endodoncia. 1997; 15(2): 72-78.

20. Rodrigues CT, de Oliveira-Santos C, Bernardineli N, et al. Prevalence and morphometric analysis of three-rooted mandibular first molars in a Brazilian subpopulation. J Appl Oral Sci. 2016; 24(5): 535-542, doi: 10.1590/1678775720150511 , indexed in Pubmed: 27812625.

21. Schneider S. A comparison of canal preparations in straight and curved root canals. Oral Surg, Oral Med, Oral Pathol. 1971; 32(2): 271-275, doi: 10.1016/00304220(71)90230-1.

22. Scott $G$, Pilloud $M$, Navega $D$, et al. rASUDAS: a new web-based application for estimating ancestry from tooth morphology. Forensic Anthropol. 2018; 1(1): 18-31, doi: 10.5744/fa.2018.0003.

23. Scott GR, Turner II CG, Townsend GC. The anthropology of modern human teeth. Dental morphology and its variation in recent and fossil Homo sapiens. 2nd ed. Cambridge University Press, Cambridge 2018.

24. Song JS, Choi HJ, Jung IY, et al. The prevalence and morphologic classification of distolingual roots in the mandibular molars in a Korean population. J Endod. 2010; 36(4): 653-657, doi: 10.1016/j.joen.2009.10.007, indexed in Pubmed: 20307739.
25. Souza-Flamini LE, Leoni GB, Chaves JF, et al. The radix entomolaris and paramolaris: a micro-computed tomographic study of 3-rooted mandibular first molars. J Endod. 2014; 40(10): 1616-1621, doi: 10.1016/j.joen.2014.03.012, indexed in Pubmed: 25260733.

26. Sperber GH, Moreau JL. Study of the number of roots and canals in Senegalese first permanent mandibular molars. Int Endod J. 1998; 31(2): 117-122, doi: 10.1046/j.13652591.1998.00126.x, indexed in Pubmed: 9868938.

27. Strmšek L, Štamfelj I. The prevalence of three-rooted permanent mandibular first molars in the population of Slovenia. Anthropol Noteb. 2019; 25(3): 69-75.

28. Turner CG. Three-rooted mandibular first permanent molars and the question of American Indian origins. Am J Phys Anthropol. 1971; 34(2): 229-241, doi: 10.1002/ ajpa.1330340207, indexed in Pubmed: 5572604.

29. Vertucci F. Root canal anatomy of the human permanent teeth. Oral Surg Oral Med Oral Pathol. 1984; 58(5): 589-599, doi: 10.1016/0030-4220(84)90085-9.

30. Visser JB. Beitrag zur Kenntnis der menschlichen Zahnwurzelformen. Hilversum: Buchdruckerei, Rotting 1948.

31. Wang Q, Yu G, Zhou XD, et al. Evaluation of x-ray projection angulation for successful radix entomolaris diagnosis in mandibular first molars in vitro. J Endod. 2011; 37(8): 1063-1068, doi: 10.1016/j.joen.2011.05.017, indexed in Pubmed: 21763895.

32. Wang $Y$, Zheng $Q H$, Zhou $X D$, et al. Evaluation of the root and canal morphology of mandibular first permanent molars in a western Chinese population by conebeam computed tomography. J Endod. 2010; 36(11): 1786-1789, doi: 10.1016/j.joen.2010.08.016, indexed in Pubmed: 20951288.

33. Yu G, Ye L, Huang D. [Clinical investigation of radix entomolaris in mandibular first molars]. Hua Xi Kou Qiang Yi Xue Za Zhi. 2012; 30(3): 259-261, indexed in Pubmed: 22768762. 